\title{
PENGARUH IKLAN UNTUNG BELIUNG BRI BRITAMA DI TELEVISI TERHADAP KEPUTUSAN KONSUMEN DALAM MENABUNG
}

\author{
Ichsan Riandy Putra, Husein Gozali \\ STIKOM The London School Public Relations, Jakarta \\ 16220110072@1spr.edu, husein.g@1spr.edu
}

Diajukan: 02-05-2018; Direview: 29-05-2018; Diterima: 28-06-2018;

\begin{abstract}
This research is about the impact of a TV Commercial of 'Untung Beliung BRI BritAma' on the decision against saving: a regression study among the residents of Anggrek Loka Complex Sector 2.1 BSD City, South Tangerang. This thesis uses the TV Commercial theory, purchase decision. The techniques used in this thesis is the purposive sampling in which not every respondent will be given the opportunity to fill in a questionnaire, but only those who match the criteria. There are 100 respondents in this thesis. Data analysis technique in use are validity, reliability, correlation, and simple linear regression test. The TV Commercial contributes $17.5 \%$ in the purchase decision. In conclusion, the respondents who are the residents of Anggrek Loka Complex Sector 2.1 BSD City, South Tangerang believe that the Untung Beliung BRI BritAma TV Commercial have a say in consumer's decision against saving in Bank BRI.
\end{abstract}

Keywords:TV Commercial, consumer's decision, regression study

\begin{abstract}
Abstrak
Penelitian ini berisi tentang penelitian yang berkaitan dengan pengruh iklan untung beliung BRI BritAma di televisi terhadap keputusan konsumen menabung: Studi regresi di masyarakat penghuni komplek anggrek loka sektor 2.1 BSD City, Tangerang Selatan. Dan memakai teori iklan televisi dan keputusan pembelian dan menggunakan teknik penenlitian nonprobability sampling yaitu purposive sampling yang mana tidak setiap responden di berikan kesempatan untuk mengisi kuisioner, hanya responden yang mempunyai kriteria penelitian saja. Responden yang terdapat dalam responden ini sejumlah 100 orang. Teknis analisa data yang di pakai adalah, uji validitas, reabilitas, uji korelasi, uji regresi linier sederhana. 17.5\%.kontribusi yang di berikan dari iklan televisi terhadap keputusan pembelian, Dapat disimpulkan bahwa responden yang merupakan masyarakat penghuni komplek anggrek loka sektor 2.1.BSD city, Tangerang Selatan, tersebut menganggap iklan Untung Beliung Britama dapat membuat keputusan konsumen untuk menabung di Bank tersebut.
\end{abstract}

Kata kunci: Iklan Televisi, keputusan konsumen, studi regresi

\section{PE}

\section{PENDAHULUAN}

Klan televisi adalah salah satu medium yang paling cocok bagi pemasar langsung untuk memperkenalkan produk yang ingin di tawarkan kepada masyarakat umum. Televisi dan radio dapat memuat informasi yang di perlukan (ditampilkan nomor telfon bebas pulsa yang dapat dihubungi serta alamat website) kepada konsumen yang ingin mendapatkan informasi atau melakukan pembelian (Moriarty, Mitchell \& wells, 2011: 573574 ). Media iklan yang paling kuat dan mampu menjangkau khalayak luas adalah televisi, dua kekuatan utama yang dimiliki oleh iklan televisi adalah kemampuannya yang dapat menjadi sarana yang efektif untuk mendemonstrasikan atribut dan produk yang di tawarkan serta bersifat persuasive karena kemampuannya yang dalam menjelaskan manfaat secara jelas ,kedua, iklan televisi juga menggambarkan pengguna serta pencitraan pengguna, kepribadian dari suatu merek dan hal hal lain yang tidak berwujud secara dramatis (kotler dan keller, 2009: 205 - 206),

Televisi termasuk kedalam medium yang bersifat teatrikal dan yang termasuk kedalam alat 
visual (video) copywriter diantaranya: karakternya kostum set dan lokasi, tata cahaya kamera dan efek khusus.Tim kreatif periklanan akan selalu memikirkan cara agar narasi yang telah di buat dapat dibagi - bagi kedalam beberapa adegan, alat audio memiliki 3 elemen utama yang di antaranya adalah musik, suara dan efek suara.tiga elemen audio yang terdapat pada televisi adalah musik, suara dan efek suara. Ketiga elemen audio tersebut digunakan secara berbeda karena di hubungkan dengan gambar (Moriarty, Mitchell \& Wells, 201:493). Demikian juga hal yang dipegang oleh iklan untung beliung Bank BRI Britama, dengan iklan yang ditayangkan di televisi diharapkan dengan adanya iklan untung beliung BRI Britama yang di jelaskan " mengumpulkan poin poin dan meningkatkan saldo serta membuka rekening Bank BRI Britama dapat meningkatkan keputusan konsumen menabung. Pada iklan versi untung beliung BRI Britama ini, Bank BRI berusaha menunjukan taktik yang berbeda dari Bank - Bank lain untuk merebut pangsa pasar dengan menggunakan marketing mix melalui penawaran (offer) terbaik yang mereka berikan kepada masyarakat seperti produk berupa layanan yang berkualitas dan hadiah ,harga (price) yang di hadiahkan untuk konsumen agar menabung di Bank BRI dan mampu bersaing dengan Bank Bank lain, saluran distribusi (place) Bank BRI yang menjangkau hampir seluruh Indonesia sehinga bisa menarik tunai dengan mudah dan dimana saja, serta komunikasi (promotion) versi untung beliung britama yang menghadiahkan mobil, motor, dll, dapat menciptakan sebuah ketertarikan konsumen untuk menabung dan juga menunjukan tentang semua keunggulan dari Bank BRI Britama.

Iklan untung beliung Bank BRI Britama ini menjadi salah satu iklan yang memiliki strategi iklan secara halus, dengan mengumpulkan poin poin bisa mendapatkan hadiah dari Bank BRI Britama seperti Mercedes, range rover dan hadiah lainnya,dengan adanya iklan ini peneliti mengambil judul pengaruh iklan untung beliung BRI Britama di televisi tahun 2016 terhadap keputusan konsumen menabung.

Berdasarkan latar belakang yang telah di uraikan oleh peneliti maka rumusan masalah adalah: Apakah terdapat pengaruh yang signifikan iklan untung beliung BRI Britama di televisi terhadap keputusan konsumen menabung di masyarakat penghuni Komplek Anggrek loka sector 2.1 BSD City Tangerang Selatan. Sehingga penelitian ini bertujuan untuk mengetahui pengaruh iklan untung beliung BRI Britama di televisi terhadap keputusan konsumen menabung studi di masyarakat penghuni komplek Anggrek loka Sektor 2.1 BSD City Tangerang Selatan. Selain itu juga untuk mengetahui pengaruh iklan untung beliung BRI Britama Terhadap nasabah.

Teori utama yang digunakan dalam penelitian ini adalah uses and gratification merupakan sebuah teori yang terfokus kepada audiens atau khalayak dibandingkan dengan isi pesan. Pendekatan pada teori ini memiliki pandangan bahwa khalayak dinilai sebagai pengguna aktif sebuah isi media dan digunakan secara pasif oleh suatu media. (Ardianto, Komala, Karlina, 2009:74)

Pendekatan Uses and gratifications berfokus pada apa yang dilakukan orang terhadap media, dimana khalayak secara aktif menggunakan media untuk memenuhi kebutuhannya. Pendekatan Uses and gratifications berfokus pada apa yang dilakukan orang terhadap media, dimana khalayak secara aktif menggunakan media untuk memenuhi kebutuhannya. Para pendirinya yaitu Katz, Blumer \&Gurevitch menjelaskan asumsi dasar dari pendekatan Uses and Gratification, yaitu : pertama , Khalayak dianggap aktif, artinya khalayak sebagai bagian penting dari penggunaan media massa diasumsikan mempunyai tujuan.Kedua , dalam proses komunikasi massa, inisiatif untuk mengaitkanpemuasan kebutuhan dengan pemilihan media terletak padakhalayak. Ketiga, Media massa harus bersaing dengan sumber-sumber lain untukmemuaskan kebutuhannya. Kebutuhan yang dipenuhi media lebihluas.Bagaimana kebutuhan ini terpenuhi melalui konsumsi mediaamat bergantung pada perilaku khalayak yang bersangkutan. Pertama Tujuan pemilih media massa disimpulkan dari data yang diberikananggota khalayak artinya, orang dianggap cukup mengerti untukmelaporkan kepentingan dan motif pada situasi-situasi tertentu, Sertaenilaian tentang arti kultural dari media massa harus ditangguhkan sebelum diteliti lebih dahulu orientasi khalayak. (Ardianto, Komala, Karlina, 2009:74) 


\section{LITERATURE DAN METODOLOGI}

Konsep dasar model ini diringkas oleh para pendirinya. Dengan model ini yang diteliti ialah (1) There are socialand psychological origin of (2) Needs, which generate (3) Expectation of (4) The mass media or other sources, which lead to (5) Differential patterns ofmedia exposure resulting in (6) Need gratifications and (7) other (oftenunintended consequences). Yaitu (1) Meneliti asal mula kebutuhan secara psikologis dan sosial. (2) Yang menimbulkan kebutuhan (3) Harapan tertentu (4) Dari media massa dan sumber-sumber lain yang membawa (5) Berbagai pola terpaan media yang berlainan (atau keterlibatan pada kegiatan lain) dan (6). Menimbulkan pemenuhan kebutuhan, dan (7) Akibat-akibat lain. (Rakhmat; 2014:65).

Menurut Rosenregen dalam Kriyantono (2008:207) pengoperasian media terdiri dari jumlah waktu yang digunakan dalam berbagai jenis media, isi media yang dapat dikonsumsi dan berbagai hubungan antara individu konsumen media dengan isi media yang dikonsumsi atau dengan media secara keseluruhan. Setelah melakukan beberapa studi di radio dan program televisi yang berbeda di inggris, McQuail, Blumer, dan Brown (1974) mengusulkan sebuah skema "media-interaksi-individu" yang sangat penting tentang kepuasan media. Yaitu :(1)Surveillance: informasi mengenai hal-hal yang mempengaruhi seseorang. (2) .Diversion / Entertainment : pelarian dari rutinitas dan masalah atau pelepasan emosi. (3). Personal identity: pemahaman diri, explorasi realitas, Penguatannilai, atau penambah keyakinan.(4) Social relationship: manfaat sosialisasi informasi dalam percakapan, pengganti media untuk perkawanan (McQuail 2010:424-425)

\section{Periklanan (Advertising)}

"Advertising is defined as any paid for of nonpersonal sommunication about an organization product, service or ide by an identified sponsor. The paid aspect of this definition reflect the fact that the space or time for an advertising message generally must be bought"

"The nonpersonal component means that advertising involves mass media (e.9., TV,
Radio, Magazine, newspaper) that can transmit a message to large groups of individual, often the same time" (Belch \& Belch, 2012:18)

Advertising adalah salah satu bentuk komunikasi yang merupakan pesan yang berisikan tentang suatu produk yang disampaikan kepada konsumen. Respons penjualan akan didapatkan apabila dvertising mampu menarik perhatian, memberikan informasi dan terkadang sedikit terhibur salah satu bentuk komunikasi pemasaran adalah advertising. Kemampuan menjangkau audiensi yang luas merupakan kekuatan advertising. (Moriaty, Mitchelss \& Wells, 2011:12 )

Periklanan memiliki 3 fungsi utama; Fungsi pertama periklanan menjalankan sebuah fungsi " informasi " iklan mampu mengkomunikasikan informasi mengenai produk, produk ciri serta lokasi penjualan dari produk tersebut. Iklan dapat memmberikan informasi kepada konsumen mengenai produk-produk baru (Lee \& Johnson, 2007:10) Philip kotler (dalam Marketing Management, 2012:526) berpendapat bahwa:

"informative advertising aims to create brand awareness and knowledge of new product or new feature of existing product"

Fungsi kedua periklanan menjalankan sebuah fungsi "persuasive" iklan bertujuan untuk membujuk para konsumen agar membeli merekmerek tertentu atau mengubah sikap mereka terhadap suatu produk atau perusahaaan . (Lee \& jhonson, 2007:10) Philip kotler dalam bukunya yang berjudul Marketing Management mengatakan bahwa :

"persuasive advertising aims to create liking, preference, conviction and purchase of product or service" (kotler dan keller, 2012:10)

Fungsi ketiga dalamperiklanan dapat menjalankan sebuah fungsi " Pengingat " iklan dapat menjadi sebuah pengingat dengan terus menerus mengingatkan kepada konsumen tentang sebuah produk yang di iklankan tersebut sehingga mereka akan membeli produk yang di iklankan tersebut dan tidak memperdulikan merek pesaing. 
(Lee \& Jhonson,2007:11)

"reinforcement advertising aims to convince current purchasers that they made the right choice " (kotler \& keller, 2012:527)

Menurut Belch and Belch iklan merupakan sebuah bentuk dari pembayaran dalam mengkomunikasikan suatu produk, layanan atau sebuah ide organisasi oleh sponsor.(Belch and Belch 2012:18) juga mengatakan bahwa tidak adanya sebuah komponen pribadi yang berarti bahwa iklan melibatkan suatu media massa, misalnya TV, Radio, Majalan, Surat Kabar, dll. yang mana media massa tersebut dapat mengirimkan pesan kepada suatu kelompok dalam individu secara besar dan bersamaan. (Belch and Belch 2012:18)

Advertising adalah salah satu bentuk komunikasi yang merupakan pesan yang berisikan tentang suatu produk yang disampaikan kepada konsumen. (Moriaty, Mitchelss \& Wells, 2011:12). Tim kreatif periklanan akan selalu memikirkan cara agar narasi yang telah di buat dapat dibagi-bagi kedalam beberapa adegan, alat audio memiliki 3 elemen utama yang di antaranya adalah musik, suara dan efek suara.tiga elemen audio yang terdapat pada televisi adalah musik, suara dan efek suara. Ketiga elemen audio tersebut digunakan secara berbeda karena di hubungkan dengan gambar (Moriarty, Mitchell \& Wells, 2011:493) kecepatan alur (pace) juga merupakan salah satu bagian penting yang harus diperhatikan oleh copywriter (Moriarty, Mitchell, \& Wells, 2011:495) sehingga dari penjelasan mengenai alat alat copywriter dalam membuat iklan televisi, maka elemen elemen, iklan televisi dapat dibagi menjadi:

Pertama, Video. Saat promotion menyaksikan sebuah iklan maka akan muncul suatu kesadaran dari tampilan yang disaksikan dibandingkan dengan hal hal lain yang disekitarnya visual gerak, dan dialog dalam film yang tidak terucap harus dapat menyampaikan pesan dengan maksimal dan hal hal tersebut harus diperhatikan oleh copywriter, efek yang dihasilkan dari sebuah cerita adalah emosi yang dapat diekspresikan dalam ekspresi wajah, gerak isyarata dan bahasa tubuh.

Kedua, Audio. Announcer dapat ditempatkan oleh copywriter untuk langsung berbicara dengan pemirsa atau berdialog dengan orang lain yang hadir atau tidak hadir dalam adegan, copywriter bertugas menulis kata-kata yang akan menjelaskan percakapan yang akan terjadi music juga di perlukan dalam Iklan sebagai latar belakang.

Ketiga, Talent. Biasa disebut juga dengan talent adalah orang yang berperan sebagai tokoh yang berbicara didalam iklan. Casting adalaha proses yang digunakan untuk mencari orang yang tepat untukmemerankan iklan, peran-peran yang dapat di perankan misalnya announcer (berperan sebagai presenter yang memperkenalkan spokesperson (berperan sebagai juru bicara), tipe karakter (wanita tua, bayi, polisi) dan selebritis.

Keempat, Props. Perlengkapan panggung (props) termasuk kedalam golongan peralatan televisi lain yang merupakan alat-alat kreatif yang dibutuhkan dalam proses pembuatan iklan disamping setting,casting, kostum dan tata cahaya yang di deskripsikan oleh copywriter dalam naskah iklan (skrip).

Kelima, Settin. Biasa yang disebut dengan set adalah tempat kegiatan pengambilan gambar yang biasanya dapat dilaksanakan di studio atau misalnya hanya menggunakan satu set meja untuk merepresentasikan kasir atau juga dapat dilaksanakan di rumah, iklan yang dibuat atau di filmkan di location (on location) adalah sebutan untuk iklan yang di luar studio yang artinya semua kru dan pemain melakukan proses pengambilan gambar di tempat yang berada jauh atau diluar studio.

Keenam, Lighting, Pencahayaan (lighting) diatur oleh sutradara namun copywriter juga dapat menspesifikasikan efek cahaya yang ingin digunakan dalam pengambilan gambar dan dapat disampaikan atau ditulis didalam skrip iklan, misalnya di dalam skrip ditulis " cahaya terang cahaya yang seolah memantul dari salju " cahaya yang menyorot wajah orang yang sedang menonton televisi.

Ketujuh, Pacing. Kecepatan alur (pacing) adalah pengaturan cepat dan lambat alur tampilan iklan yang ingin di tampilkan,beberapa pesan yang ingin disampaikan dapat dikembangkan dengan menggunakan alur cepat atau lambat yang biasanya oleh copywriter. 
Model Perilaku Konsumen dan Pengambilan Keputusan

Menurut Kotler dan Keller dalam Sabran (2009:178), Perilaku pembelian konsumen di pengaruhi oleh faktor-faktor yaitu Faktor Budaya, Faktor Sosial, dan Faktor Pribadi. otler dan Keller juga mengungkapkan bahwa "keputusan dari suatu pembelian konsumen merupakan sebuah tindakan individu baik secara langsung ataupun tidak langsung dan terlibat dalam sebuah usaha dalam memperoleh produk dan jasa sesuai dengan kebutuhannya."

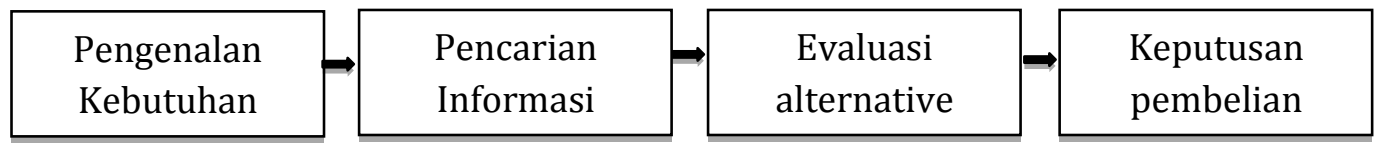

Gambar 1. Tahap Proses Pengambilan Keputusan Pembelian

Sumber: Kotler dan Keller (2009:184)

Proses pertama yang dipaparkan pada gambar di atas adalah pengenalan kebutuhan dan proses dimulai ketika pembeli menganalisa masalah atau kebutuhan.kebutuhan tersebut dapat di cetuskan oleh rangsangan internal (lapar, haus, dan sebagainya) dan ekternal adalah (menonton iklan televisi). Para pemasar perlu mengidentifikasi keadaan yang memicu kebutuhan tertentu dengan mengumpulkan informasi dari sejumlah kosumen. Mereka kemudian dapat menyusun startegi pemasaran yang mampu memacu minat konsumen.

Hal ini sangat penting pada pembelian dengan kebebasan memilih (discretionary) misalnya pada barang barang mewah,paket liburan dan opsi hiburan. Motivasi konsumen perlu ditingkatkan sehingga pembeli potensial memberikan perimbangan yang seirus.

Diikuti dengan bagan selanjutnya yaitu pencarian informasi yang dimana konsumen yang terangsang kebutuhannya akan terdorong untuk mencari informasi yang lebih banyak. Kita dapat membaginya ke dalam dua level rangsangan. Situasi pencarian informasi yang lebih ringan dinamakan penguatan perhatian.pada level ini, orang hanya sekedar lebih peka terhadap informasi produkPada level selanjutnya orang itu akan mulai aktif mencari informasi untuk mempelajari produk tersebut. Yang menjadi perhatian utama pemasar adalah sumber-sumber informasi utama yang menjadi acuan konsumen dan relative tiap sumber terhadap keputusan pembelian.

Lalu terdapat beberapa proses evaluasi alternative untuk keputusan dan model-model terbaru yang memandang proses evaluasi konsumen sebagai proses yang berorientasi kognitif.yaitu model tersebut menganggap konsumen membentuk penilaian atau produk dengan sangat sadar dan rasional. Beberapa konsep dasar akan membantu memahami proses evaluasi konsumen. Pertama,konsumen berusaha memenuhi kebutuhan.kedua, konsumen mencari manfaat tertentu dari solusi produk. Ketiga, konsumen memandang masing masing produk sebagai sekumpulan atribut dengan kemapuan yang berbeda beda dalam member manfaat yang di gunakan untuk memuaskan kebutuhan itu.

Setelah mengalamibeberapa evaluasi alternative lalu masuk tahap selanjutnya yaitu keputusan pembelian. Dalam tahap evaluasi,para konsumen membentuk preferensi atas merek-merek yang ada di dalan kumpulan. Pilihan konsumen juga dapat membentuk niat untuk membeli merek yang dia sukai, dalam maksud melaksanakan pembelian,konsumen bisa mengambil lima sub keputusannya yaitu merek, dealer, kualitas, waktu dan lain lain.

\section{TEMUAN DAN DISKUSI}

Hasil perhitungan jumlah sampel yang akan diteliti setelah dihitung menggunakan rumus slovin adalah sebanyak 99.83 sampel dan untuk mempermudah perhitungan, maka hasil perhitungan tersebut di bulatkan menjadi 100 orang. Penelitian ini menggunakan teknik nonprobabilitas dengan memilih purposive sampling sebagai salah satu bagian dari teknik sampling. Menurut Sugiyono, (2011: 122-123) teknik pengambilan sampel yang digunakan adalah rancangan sampel nonprobabilitas (Nonprobability sampling design) yang tidak memberikan peluang kesempeatan yang sama untuk setiap unsur atau anggota populasi untuk dipilih menjadi anggota sampel. Menurut 
(Kriyantono, 2006:158) purposive sampling dapat digunakan apabila objek yang akan diteliti (sample) adalah orang orang yang telah diseleksi atas kriteria-kriteria tertentu yang di buat oleh orang yang akan melakukan penelitian (peneliti) yang didasari oleh tujuan penelitian dan orangorang yang tidak disesuai dengan kriteria yang terdapat didalam populasi tidak akan dijadikan sampel.

Data primer adalah data yang dikumpulkan dengan menggunakan sumber primer, yaitu sumber data yang langsung memberikan data kepada pengumpul data.Data primer yang didapat dalam penelitian ini adalah berupa hasil kuisoner (angket). Sugiyono berpendapat, (2010:137) data primer adalah data yang dikumpulkan dengan menggunakan sumber primer, yaitu sumber data yang langsung memberikan data kepada pengumpul data.Data primer yang didapat dalam penelitian ini adalah berupa hasil kuisoner (angket).

Data sekunder adalah data yang berasal dari sumber sekunder, yaitu sumber data yang tidak langsung memberikan data kepada pengumpul data, misalnya lewat orang lain, atau dokumen (Sugiyono, 2010:137). Data sekunder diperoleh melalui buku, internet,media massa, dan sumbersumber berkaitan lainnya. Teknik analisis data pada penelitian ini yaitu menggunakan uji validitas, uji reliabilitas, analisis korelasi dengan rumus pearson correlation, lalu analisis regresi berganda (Hasan, 2002:114).

Berdasarkan hasil penelitian dilihat bahwa jumlah responden yang berusia di atas 27 tahun lebih dominan apabila dibandingkan dengan responden lainnya yaitu sebanyak 58 responden atau 58,0\%. Responden yang berumur 24 sampai 27 tahun berjumlah 34 responden atau 34,0\%, responden yang berumur 21 tahun sampai 23 tahun mempunyai responden yang berjumlah 6 responden atau $6.0 \%$ dan responden yang berusia dari 18 tahun sampai 20 tahun berjumalh 2 responden atau $2.0 \%$.

Berdasarkan data bahwa jumlah responden yang berjenis kelamin Laki-Laki lebih dominan apabila dibandingkan dengan responden Perempuan yaitu sebanyak 71 responden atau $71,0 \%$. Responden yang berjenis kelamin wanita berjumlah 29 responden atau $29,0 \%$.
Responden yang berpendidikan terakhir S1 mempunyai responden yang lebih dominan di bandingkan dengan yang lain dengan jumlah responden sebebsar 53 atau $53.0 \%$, responden yang berpendidikan terakhir S2 mempunyai responden sebanyak 30 atau $30 \%$, responden yang berpendidikan terakhir SMA mempunyai responden sejumlah 14 atau $14,0 \%$, dan responden dengan pendidikan terakhir S3 jumlah 3 atau 3.0\%

Berdasarkan data yang melihat iklan 2 kali dalam seminggu lebih dominan dengan jumlah 41 responden atau $41,0 \%$ dibandingkan dengan responden yang melihat iklan 3 kali dalam seminggu, yaitu sejumlah 29 responden atau $29,0 \%$, responden yang melihat iklan 1 kali dalam seminggu sejumlah 21 responden atau $21,0 \%$. dan responden yang melihat iklan lebih dari 4 kali dalam seminggu yaitu sejumlah 9 atau $9.0 \%$.

Untuk mengetahui seberapa kuat atau lemahnya hubungan antara iklan untung beliung BRI BritAma di televisi terhadap keputusan konsumen menabung, dilakukan analisis korelasi dengan menggunakan perhitungan korelasi tingkat Pearson.

Tabel 1. Hasil Uji Korelasi( Pearson Correlaation)

\begin{tabular}{llr|r} 
& & \multicolumn{1}{c}{ Iklan } & \multicolumn{1}{c}{ Keputusan } \\
\hline Iklan & Pearson Correlation & 1 & $.418^{* *}$ \\
& & & \\
\cline { 2 - 4 } & Sig. (2-tailed) & 100 & .000 \\
\cline { 2 - 4 } Keputusan & Pearson Correlation & $.418^{* *}$ & 100 \\
& & & \\
& Sig. (2-tailed) & .000 & \\
\cline { 2 - 4 } & $\mathrm{N}$ & 100 & 100 \\
\hline **. Correlation is significant at the 0.01 level (2-tailed).
\end{tabular}

Sumber Data olahan 2016

Berdasarkan tabel diatas dapat diketahui bahwa hasil korelasi antara variabel X (iklan televisi) dan variabel Y (keputusan membeli) adalah sebesar 0,418 . Hal tersebut dapat diinterpretasikan sebagai berikut, terdapat hubungan korelasi positif yang sedang antara variabel X dan Y. (Bungin, 2005:184)

Untuk mengetahui seberapa seberapa besar pengaruh antara iklan untung beliung BRI BritAma di televisi terhadap keputusan konsumen menabung, dilakukan analisis korelasi dengan menggunakan perhitungan regresi linier sederhana tingkat Pearson. Perhitungan dilakukan dan diolah 
dengan menggunakan program SPSS.

\begin{tabular}{ll|r|r|r} 
& \multicolumn{4}{c}{ Tabel 2. Model Summary } \\
Model & R & R Square & $\begin{array}{c}\text { Adjusted R } \\
\text { Square }\end{array}$ & $\begin{array}{l}\text { Std. Error of } \\
\text { the Estimate }\end{array}$ \\
\hline 1 & $.418^{\mathrm{a}}$ & .175 & .167 & 2.409 \\
\hline
\end{tabular}

a. Predictors: (Constant), Iklan

b. Dependent Variable: Keputusan
Dari tabel diatas dapat diketahui bahwa nilai $\mathrm{R}$ Square dari analisis regresi yang dilakukan adalah 0,175 . Hal ini menunjukkan bahwa variabel $Y$ (keputusan membeli) dapat dijelaskan dengan variabel X (iklan televisi) dengan nilai sebesar $17.5 \%$. Sementara $82.5 \%$ dipengaruhi oleh faktorfaktor eksternal lainnya.

Sumber Data olahan 2016

Tabel 3. Koefisien Regresi Sederhana

\begin{tabular}{|c|c|c|c|c|c|c|}
\hline \multirow{2}{*}{\multicolumn{2}{|c|}{ Model }} & \multicolumn{2}{|c|}{$\begin{array}{c}\text { Unstandardized } \\
\text { Coefficients }\end{array}$} & \multirow{2}{*}{$\begin{array}{c}\text { Standardized } \\
\text { Coefficients } \\
\text { Beta }\end{array}$} & \multirow[b]{2}{*}{$\mathrm{t}$} & \multirow[b]{2}{*}{ Sig. } \\
\hline & & B & Std. Error & & & \\
\hline \multirow[t]{2}{*}{1} & (Constant) & 23.040 & 4.202 & & 5.484 & .000 \\
\hline & Iklan & .327 & .072 & .418 & 4.558 & .000 \\
\hline
\end{tabular}

a. Dependent Variable: Keputusan

Sumber Data olahan 2016

\section{SIMPULAN}

Persamaan regresi linear sederhana yang menunjukkan besarnya pengaruh tayangan iklan televisi terhadap keputusan membeli menurut pelanggan adalah $\mathrm{Y}=23,040+0,327 \mathrm{X}$. Arti dari persamaan regresi tersebut adalah sebagai berikut: Nilai konstanta (a) adalah 23,040, artinya jika tayangan iklan televisi memiliki nilai 0 , maka keputusan membeli bernilai sebesar 23,040. Nilai koefisien regresi dari variabel keputusan membeli (b) adalah 0,327. Dapat diartikan bahwa setiap peningkatan tayangan iklan televisi (variabel $\mathrm{X})$ sebesar satu unit, akan meningkatkan nilai keputusan membeli (variabel Y) sebesar 0,327 unit.

Setelah mendapatkan data kuesioner yang di sebarkan pada masyarakat penghuni komplek anggrek loka 2.1, peneliti mendapatkan data dan diuji validitas dan reabilitas pada pernyataan yang tertera pada kuesioner tersebut. Pernyataan yang diajukan pada kuesioner tersebut sebanyak 24 pernyataan yang dibagi kedalam dua variabel, yaitu variabel $\mathrm{X}$ (iklan televisi) dan variabel $\mathrm{Y}$ keputusan pembelian sebanyak 14 pernyataan pada variabel $\mathrm{X}$ dan 10 pernyataan pada variabel Y. Setelah melakukan uji validitas dan uji reabilitas dapat disimpulkan bahwa pernyataan yang diajukan valid dan jika disebarkan kembali akan mendapatkan hasil yang sama.
Dari tabel model summary dapat diketahui bahwa besarnya nilai $R$ Square dari analisis regresi yang dilakukan adalah adalah 0,175 yang berarti $17.5 \%$. Hal ini menunjukan bahwa variabel keputusan pembelian (Y) dapat dijelaskan oleh variabel iklan televisi (X). Sedangkan sisa nya Sementara $82.5 \%$ dipengaruhi oleh faktor-faktor eksternal lainnya.

Pada hasil table regresi besarnya pengaruh iklan televisi terhadap keputusan konsumen menabung menurut masyarakat adalah $\mathrm{Y}=23,040+0,327 \mathrm{X}$ maka bisa di jelaskan bahwa(a) adalah 23,040, artinya jika tayangan iklan televisi memiliki nilai 0 , maka keputusan membeli bernilai sebesar 23,040. Nilai koefisien regresi dari variabel keputusan membeli (b) adalah 0,327. Dapat diartikan bahwa setiap peningkatan tayangan iklan televisi (variabel X) sebesar satu unit, akan meningkatkan nilai keputusan membeli (variabel Y) sebesar 0,327 unit. nilai signifikasi bernilai 0,000 atau lebih kecil dari 0,05 sehingga. Dapat disimpulkan bahwa variable iklan televisi di pengaruhi oleh variabel keputusan pembelian.

Berdasarkan Hasil penelitian yang telah didapatkan dan hasil penyebaran kuisioner yang telah di lakukan oleh peneliti.maka dapat di tarik kesimpulan bahwa iklan televisi memiliki hubungan terhadap keputusan pembelian sebesar 0,418 . Hal tersebut dapat diinterpretasikan sebagai 
berikut, terdapat hubungan korelasi positif yang sedang antaara variable $\mathrm{x}$ dan $\mathrm{y}$.

Berdasarkan hasil penelitian yang telah di lakukan dan di kumpulkan dan di olah menggunakan program SPSS, Maka dapat disimpulkan terdapat pengaruh antara iklan televise dengan keputusan pembelian. Hasil tersebut diketahui dari nilai signifikasi (sig) nilai signifikansi untuk variabel independen memiliki nilai sebesar 0,000.

Berdasarkan signifikansi, apabila nilai signifikansi lebih kecil dari 0,05 berarti Ho ditolak. Sebaliknya, apabila signifikansi lebih besar dari 0,05 berarti Ho diterima. Oleh karena nilai signifikasi bernilai 0,000 atau lebih kecil dari 0,05 maka Ho ditolak dan Ha diterima. Dapat disimpulkan bahwa terdapat pengaruh antara variable $\mathrm{X}$ terhadap variable $\mathrm{Y}$. Besar kontribusi yang di berikan oleh variable iklan telvisi (x) terhadap keputusan pembelian (y) dapat dilihat dari nilai $R$ Square sebesar 0,175 yang artinya $R$ Square dari analisis regresi yang dilakukan adalah 0,175 . Hal ini menunjukkan bahwa variabel $\mathrm{Y}$ (keputusan menabung) dapat dijelaskan dengan variabel X (iklan televisi) dengan nilai sebesar $17.5 \%$. Sementara $82.5 \%$ dipengaruhi oleh faktorfaktor eksternal lainnya.

Berdasarkan hasil analisa yang dilakukan berkaitan dengan pengaruh iklan untung beliung BRI BritAma di televisi, maka peneliti memberikan beberapa saran akakdemis agar dilakukan penelitian lebih lanjut dan mendalam yang berkaitan denngan variable-variable lain yang memiliki hubungan dan pengaruh terhadap keputusan pembelian sehingga akan di dapatkan hasil penelitian yang lebih baik berkaitan dengan variable-variable yang memiliki hubungan dan pengaruh dengan keputusan pembelian. Peneliti berharap agar hasil penelitian ini dapat di jadikan panduan dalam melakukan lain penelitian yang berkaitan dengan iklan televise terhadap keputusan pembelian. Dengan hasil penelitian ini, di harapkan dapat bermanfaat dalam dunia periklanan dan pemasaran karena periklanan merupakan salah satu komponen dari komunikasi pemasaran

Sementara untuk saran praktis agar seluruh anggota yang memiliki dan memberikan kontribusi dalam tayangan iklan untung beliung bri britama untuk dapat mengevaluasi iklan bri tersebut yang di tayangkan sehingga dapat membentuk masyarakat untuk menabung di bank bri. Dan diharapkan PT Bank Rakyat Indonesia dapat memperbaiki serta mengembangkan konsep promosi serta penjualan produk tabungan yang lebih baik.

\section{DAFTAR PUSTAKA}

Ardianto, E. Komala, L., \&Karlinah, S. (2009). Komunikasi Massa Suatu

Pengantar Edisi Revisi. Bandung, Indonesia: Simbiosa Rekatama Media

Belch, G. E., Belch, M. A. (2009). Advertising and Promotion : An Intergrated Marketing Communication Perspective. $8^{\text {th }}$ Edition. New York : McGrawh-ill

Bungin, B. (2005). Metodologi Penelitian Kuantitatif. Jakarta: Prenada Media.

Hasan, M Iqbal. 2002. Pokok-pokok Materi Statistika 1 (Statistik Deskriptif). Edisi Kedua. PT. Bumi Aksara. Jakarta

Kriyantono, R. (2006) Teknik praktis riset komunikasi: disertai contoh praktis riset media public relation, Advetising, komunikasi pemasaran. Jakarta kenacana.

Kriyantono, R. (2008) Teknik praktis riset komunikasi: disertai contoh praktis riset media public relation, Advetising, komunikasi pemasaran. Jakarta kenacana

Kotler \& Keller, (2009,p.184) Model keputusan pembelian Marketing Management. 14 Global Edition England: Pearson Educated Limited.

Kotler, P, dan Amstrong G. 2012, prinsip - prinsip pemasaran Edisi 13, jilid 1. Jakarta : Erlangga

Kotler, P. \& Keller, K.L. (2012) Marketing Management. Twelth Edition New Jersey : pearson

Kotler, Philip dan kelle, kevin lane 2009, Manajemen Pemasaran. Edisi ketigabelas jilid 1. Alih bahasa bob sabran jakarta, Penerbit Erlangga

Lee, M. dan Jhonson C. (2007).Prinsip-Prinsip pokok periklanan dalam Perspektif Global. Jakarta: Kencana.

Marioarty, S.M. \& Wells, W. (2011) Advertising. 
Jakarta: Kencana

McQuail, D. (Eds.). (2010). Teori Komunikasi Massa. Jakarta, Indonesia: Salemba.

Rakhmat, J. 2013. Psikologi Komunikasi. Bandung: PT. Remaja Rosda Karya

Schiffman \& kanuk (2007). Perilaku Konsumen edisi kedua Jakarta PT.Index Grmedia
Sugiyono, 2011. Metode Penelitian Kuantitaif Kualitatif dan R \& B, Bandung: Alfabeta.

Sugiyono. 2010. Metode Penelitian Pendidikan Pendekatan Kuantitatif, kualitatif, dan R\&D. Bandung: Alfabeta. 